\title{
The Analgesic Effects of Morphine and Tramadol Added to Intra-articular Levobupivacaine-Tenoxicam Combination for Arthroscopic Knee Surgery on Postoperative Pain; a Randomized Clinical Trial
}

\author{
Ebru Gelici Oral ${ }^{1}$; Ayse Hanci ${ }^{2}$; Gulcihan Ulufer Sivrikaya ${ }^{3, *}$; Hale Dobrucali ${ }^{2}$; Leyla \\ Turkoglu Kilinc ${ }^{2}$ \\ ${ }^{1}$ Department of Anesthesiology, Hatay Obstetrics and Gynecology and Pediatrics Hospital, Hatay, Turkey \\ ${ }_{3}^{2}$ Department of Anesthesiology and Reanimation, Sisli Etfal Training and Research Hospital, Istanbul, Turkey \\ ${ }^{3}$ Department of Anesthesiology and Reanimation, Antalya Training and Research Hospital, Antalya, Turkey \\ ${ }^{*}$ Corresponding author: Gulcihan Ulufer Sivrikaya, Department of Anesthesiology and Reanimation, Antalya Training and Research Hospital, Antalya, Turkey. Tel: +90-5322924173, \\ Fax:+90-2422285047, E-mail: ulufers@gmail.com
}

Received: September 28, 2014; Revised: November 13, 2014; Accepted: December 19, 2014

\begin{abstract}
Background: Arthroscopic knee surgery is commonly performed as an outpatient procedure and is often associated with postoperative pain.

Objectives: We aimed to compare the effects of intra-articular levobupivacaine-tenoxicam-tramadol and levobupivacaine-tenoxicammorphine combinations on postoperative pain in patients undergoing elective arthroscopic knee surgery.

Materials and Methods: $\mathrm{A}$ total of 90 ASA I-II patients undergoing elective arthroscopic meniscectomy under general anesthesia were enrolled. The participants were randomly allocated to three groups to receive the following intra-articular medications after completion of the surgery and before deflation of the tourniquet: Group S, $20 \mathrm{~mL}$ of saline; Group T, $35 \mathrm{mg}$ of levobupivacaine, $20 \mathrm{mg}$ of tenoxicam, and $100 \mathrm{mg}$ of tramadol in $20 \mathrm{~mL}$ saline; and Group M, $35 \mathrm{mg}$ of levobupivacaine, $20 \mathrm{mg}$ of tenoxicam, and $4 \mathrm{mg}$ of morphine in $20 \mathrm{~mL}$ saline. Visual analogue scale values at rest (VASr) and at active flexion of knee (VASa) at postoperation hours 1, 2, 4, 8, 12, and 24, duration of analgesia, total analgesic consumption, and number of rescue analgesia at 24 hours were evaluated.

Results:VASr and VASa were significantly higherin groupSin comparison to other groups $(\mathrm{P}<0.05)$. Duration of analgesia was significantly longer in Group T and Group M than in Group S $(\mathrm{P}<0.05)$. The difference between group T and group $\mathrm{M}$ was also significant $(\mathrm{P}<0.05)$. Number of rescue analgesia and total analgesic consumption at postoperative hour 24 was significantly fewer in group $\mathrm{M}$ compared with other groups $(\mathrm{P}<0.05)$.

Conclusions: Intra-articular levobupivacaine-tenoxicam-morphine combination provides effective pain relief, longer analgesic duration, and less analgesic requirement when compared with intra-articular levobupivacaine-tenoxicam-tramadol combination and saline after knee arthroscopic surgery.
\end{abstract}

Keywords: Pain; Morphine; Tramadol; Tenoxicam

\section{Background}

Arthroscopic knee surgery is commonly performed as an outpatient procedure and is often associated with postoperative pain. Effective pain relief is important after arthroscopic knee surgery to permit early discharge and improve patient comfort and mobility (1). Intra-articular (IA) analgesia is a popular technique of pain management after arthroscopic knee surgery. Local anesthetics, especially bupivacaine, are the most common drugs administered intra-articularly. Nonetheless, the analgesic effect does not last long. Moreover, the IA use of bupivacaine has been shown to be toxic to chondrocytes (2) and decreases the number of chondrocytes without causing tissue loss (3). However, there is no study regarding IA levobupivacaine toxicity and data on its IA administration is limited in the literature. Many researches have been done to find the ideal regime for sufficient long-lasting postoperative analgesia such as using opioids, neostigmine, $\alpha_{2}$-agonists, or nonsteroidal anti-inflammatory drugs (NSAIDs) separately, in combinations with each other, or with local anesthetics (4-9). NSAIDs mainly act peripherally to reduce antinociception. NSAID may also reduce pain by modifying the local inflammatory process. As the pain of arthroscopy arises in the joint, it is logical to use a peripherally acting drug at the site of injury (9).

\section{Objectives}

In this study, we evaluated and compared the efficacy of IA administration of a long-lasting nonsteroidal analgesic drug, namely, tenoxicam, combined with a local anesthetic, i.e. levobupivacaine, and tramadol or morphine on postoperative analgesia after arthroscopic knee surgery. 


\section{Materials and Methods}

After Ethics Committee of Sisli Etfal Training and Research Hospital approval and obtaining written informed consent, 90 patients aged between 20 to 45 years with ASA class I or II, undergoing elective arthroscopic meniscectomy, were enrolled in this prospective, randomized, double-blind study. Patients that received NSAIDs or narcotics in five days before operation, patients allergic to one of the study drugs, and those with alcohol or drug abuse were excluded. All patients were preoperatively instructed to use 10 -cm visual analog scale $($ VAS $)(0=$ no pain; $10=$ the worst imaginable pain $)$. Preoperative baseline values of pain were evaluated at rest and at 90 degrees of flexion. None of the patients received premedication. Standard monitoring techniques were used including electrocardiography, noninvasive blood pressure monitoring, and end-tidal carbon dioxide and peripheral oxygen saturation (Drager, Infinity Vista, Germany). Anesthesia was induced with intravenous administration of $2 \mathrm{mg} / \mathrm{kg}$ of propofol, $2 \mu \mathrm{g} / \mathrm{kg}$ of fentanyl, and $0.3 \mathrm{mg} / \mathrm{kg}$ of atracurium besylate and was maintained with $50 \%$ nitrous oxide in oxygen and $5 \%$ to $6 \%$ desflurane via a laryngeal mask airway.

A thigh pneumatic tourniquet at a pressure of 250 to $300 \mathrm{mmHg}$ was applied on the same side of surgery. One surgeon performed surgical procedures using a standard surgical technique. When the surgery was completed, patients were randomly allocated to one of the three groups of 30 with the random selection of one of the envelopes in which assigned group was written. The drugs were prepared in a separate room and given to the surgical team at end of surgery. The drug solution was standardized as a total of $20-\mathrm{mL}$ volume. Group $\mathrm{S}$ received $20 \mathrm{~mL}$ of isotonic saline; Group M received $35 \mathrm{mg}$ of levobupivacaine ( $5 \mathrm{mg} / \mathrm{mL}), 20 \mathrm{mg}$ of tenoxicam, and $4 \mathrm{mg}$ of morphine in $20 \mathrm{~mL}$ saline; and Group T received $35 \mathrm{mg}$ of levobupivacaine ( $5 \mathrm{mg} / \mathrm{mL}$ ), $20 \mathrm{mg}$ of tenoxicam, and $100 \mathrm{mg}$ of tramadol in $20 \mathrm{~mL}$ saline. The study solutions were injected into the knee joint through the arthroscopic portal by the surgeon at the end of surgery and ten minutes before tourniquet release. All operations and IA injections were performed by the same surgeon who was blinded to the content of the syringe. No IA drain was used. After completion of the anesthesia, patients were transferred to the postoperative care unit. Pain was assessed with VAS (it is in our clinical protocol to assess pain with VAS) by questioning the patients at hours 1, 2, 4, 8, 12, and 24 postoperatively, at rest (VASr) and during active movement of the knee at $90^{\circ}$ flexion (VASa). When patients complained of pain (VAS score $>3$ ), they were given $500 \mathrm{mg}$ of paracetamol intravenously as rescue medication and total consumption was recorded over 24 hours. Patients' required rescue analgesia, number of rescue analgesia at 24 hours of operation, and duration of analgesia, which was considered as the time from IA injection to first analgesic requirement, were recorded. Side effects such as vomiting, nausea, sedation, dry mouth, and any other adverse events were observed during the study period.

Primary end-points were VAS pain scores at rest and during active flexion of knee. Secondary end-points were duration of analgesia, number of rescue analgesia, total analgesic consumption at 24 hours of operation, and number of patients requiring rescue analgesia.

The data were presented as mean \pm SD or as a proportion with a $95 \%$ CI. Categorical data were analyzed by a Chi square test. Basic characteristics data (age, height, and weight), dose of analgesic, and duration of surgery and analgesia were analyzed by using one-way ANOVA. When a significant result was obtained, a post hoc test was performed to determine significance among groups. Pain scores were evaluated using the Kruskal-Wallis test. When a significant result was obtained, the Mann-Whitney $U$ test was performed to determine significant difference belongs to which group; an adjustment was made for multiple comparisons. P values $<0.05$ were considered statistically significant. A SD of 1.35 point was found in our pilot study. A minimum simple size of 87 (29 in each group) was required to detect at least a one point difference in the VAS scores between groups at the measurement times with a significant clinical difference at the $5 \%$ significance level.

\section{Results}

Demographic and surgical data are presented in Table 1. There were no statistically significant differences among the groups with respect to age, sex and duration of surgery.

\begin{tabular}{|c|c|c|c|c|}
\hline Variables & Group $\mathbf{M}^{\mathrm{b}}$ & Group $\mathrm{T}^{\mathrm{C}}$ & Group $S^{d}$ & PValue \\
\hline Age, y & $32.83 \pm 10.14$ & $33.67 \pm 9.60$ & $30.63 \pm 6.50$ & 0.64 \\
\hline Gender & & & & 0.76 \\
\hline Female & 11 & 15 & 9 & \\
\hline Male & 19 & 15 & 21 & \\
\hline Duration of operation, min & $95.8 \pm 11.6$ & $98.3 \pm 16.9$ & $95.6 \pm 12.1$ & 0.68 \\
\hline
\end{tabular}

${ }^{a}$ Data were expressed as mean \pm SD or No.

b Received $35 \mathrm{mg}$ of levobupivacaine $(5 \mathrm{mg} / \mathrm{mL}), 20 \mathrm{mg}$ of tenoxicam, and $4 \mathrm{mg}$ of morphine in $20 \mathrm{~mL}$ saline.

c Received $35 \mathrm{mg}$ of levobupivacaine $(5 \mathrm{mg} / \mathrm{mL}), 20 \mathrm{mg}$ of tenoxicam, and $100 \mathrm{mg}$ of tramadol in $20 \mathrm{~mL}$ saline.

$\mathrm{d}$ Received $20 \mathrm{~mL}$ of isotonic saline. 
Oral EG et al.

\begin{tabular}{|c|c|c|c|c|}
\hline Time, $\mathbf{h}$ & Group $M^{b}$ & 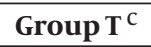 & Group $S^{d}$ & PValue \\
\hline Preoperation & $2.16 \pm 1.95$ & $1.97 \pm 2.39$ & $1.75 \pm 1.4$ & 0.684 \\
\hline \multicolumn{5}{|l|}{ Postoperation } \\
\hline Hour 1 & $1.8 \pm 1.15$ & $2.26 \pm 2.03$ & $1.88 \pm 1.24$ & 0.089 \\
\hline Hour 2 & $1.63 \pm 1.15^{\mathrm{e}}$ & $1.6 \pm 1.47^{\mathrm{e}}$ & $2.36 \pm 1.32$ & 0.042 \\
\hline Hour 4 & $1.53 \pm 1.45^{\mathrm{e}}$ & $1.82 \pm 1.68^{\mathrm{e}}$ & $2.03 \pm 0.98$ & 0.004 \\
\hline Hour 8 & $1.23 \pm 0.81^{\mathrm{f}}$ & $1.8 \pm 1.37^{\mathrm{e}}$ & $2.1 \pm 1.04$ & 0.002 \\
\hline Hour 12 & $1.36 \pm 1.06^{\mathrm{e}}$ & $1.36 \pm 1.27^{\mathrm{e}}$ & $1.9 \pm 1.32$ & 0.003 \\
\hline Hour 24 & $1.06 \pm 0.77^{\mathrm{e}}$ & $0.93 \pm 0.9^{\mathrm{e}}$ & $1.52 \pm 1.18$ & 0.003 \\
\hline \multicolumn{5}{|c|}{$\begin{array}{l}\text { a Data were expressed as mean } \pm \text { SD. } \\
\text { b Received } 35 \mathrm{mg} \text { of levobupivacaine }(5 \mathrm{mg} / \mathrm{mL}), 20 \mathrm{mg} \text { of tenoxicam, and } 4 \mathrm{mg} \text { of morphine in } 20 \mathrm{~mL} \text { saline. } \\
\text { c Received } 35 \mathrm{mg} \text { of levobupivacaine }(5 \mathrm{mg} / \mathrm{mL}), 20 \mathrm{mg} \text { of tenoxicam, and } 100 \mathrm{mg} \text { of tramadol in } 20 \mathrm{~mL} \text { saline. } \\
\text { d Received } 20 \mathrm{~mL} \text { of isotonic saline. } \\
\text { e } \mathrm{P}<0.05 . \\
\mathrm{f} \quad \mathrm{P}<0.01 \text { compared to group C. }\end{array}$} \\
\hline
\end{tabular}

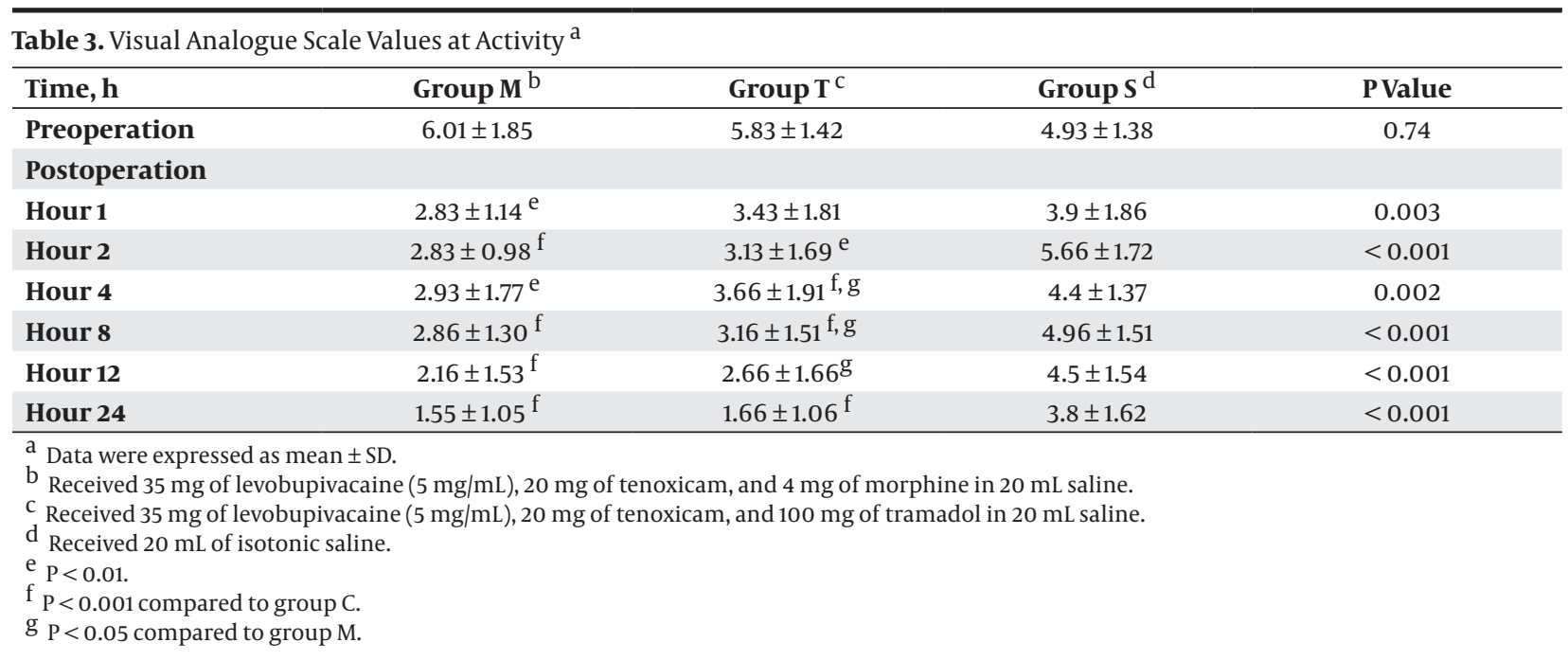

\subsection{Pain at Rest and During Active Flexion}

No significant differences were found among the groups in preoperative VAS scores at rest and during active flexion. VASr scores were significantly higher in Group $S$ in comparison with Group T and Group $M$ at all of the time points, except at 1 hour after operation (Table 2 ). In Group $\mathrm{S}$, the VASa scores were significantly higher than those in Group M at all of the time points and then those in Group $\mathrm{T}$ at $2,8,12$, and 24 hours of surgery $(\mathrm{P}<0.05)$ (Table 3 ). There was no difference between Groups T and $\mathrm{M}$ in VASr scores. VASa was significantly higher in Group $\mathrm{T}$ than in Group M at postoperative hours 4, 8, and $12(\mathrm{P}<0.05)$.

\subsection{Analgesic Consumption}

The percentage of patients required rescue analgesia in Group $S$ was significantly more than those in Groups $\mathrm{T}$ and $M$ at postoperative hours 2, 8, 12, and 24 (Table 4). No patients from Group $\mathrm{T}$ and Group $M$ required more than twice supplemental analgesic. In Group S, supplemental analgesic we administered in first 24 hours of operation as follows: three times for 10 patients, four times for four patients, and five times for two patients were used.

Number of rescue analgesia during the first 24 hours of operation was significantly lower in Group M compared with Groups T and S (Table 4). Duration of analgesia was significantly longer in Groups $T$ and $M$ than in Group S (Table 4). The difference between Group $\mathrm{T}$ and Group $M$ was also significant (Table 4). Total analgesic consumption during the first 24 hours of operation was 31.5, 13.0, and $6.5 \mathrm{mg}$ in respectively Groups S, T, and M with Groups $M$ having significant difference with other groups $(\mathrm{P}<0.05)$.

\subsection{Adverse Effects}

No statistical difference was obtained regarding the incidence of adverse effects among three groups ( $\mathrm{P}>$ $0.05)$. The number of patients who experienced nausea in Groups S, T, and M were one, two, and two, respectively. None of patients had vomiting or signs of sedation. In Group M, one patient experienced pruritus. 
Oral EG et al.

\begin{tabular}{lcccc}
\hline Table 4. Postoperative Analgesia in Groups ${ }^{\mathrm{a}}$ & & & \\
\hline Variables & Group M $^{\mathrm{b}}$ & Group T $^{\mathrm{c}}$ & Group S $^{\mathrm{d}}$ & P Value \\
\hline Patients required rescue analgesia & $12(40)$ & $18(60)$ & $30(100)$ & 0.032 \\
Number of rescue analgesia at hour 24 of operation, mean No. & $0.43 \pm 0.28$ & $0.86 \pm 0.48^{\mathrm{e}}$ & $2.66 \pm 0.88^{\mathrm{f}}$ & 0.0046 \\
Duration of analgesia, min & $340 \pm 160^{\mathrm{g}}$ & $283 \pm 227^{\mathrm{e}}$ & $152 \pm 86$ & 0.0002 \\
\hline
\end{tabular}

a Data were expressed as No. (\%) or mean \pm SD.

b Received $35 \mathrm{mg}$ of levobupivacaine ( $5 \mathrm{mg} / \mathrm{mL}), 20 \mathrm{mg}$ of tenoxicam, and $4 \mathrm{mg}$ of morphine in $20 \mathrm{~mL}$ saline.

C Received $35 \mathrm{mg}$ of levobupivacaine $(5 \mathrm{mg} / \mathrm{mL}), 20 \mathrm{mg}$ of tenoxicam, and $100 \mathrm{mg}$ of tramadol in $20 \mathrm{~mL}$ saline.

$\mathrm{d}$ Received $20 \mathrm{~mL}$ of isotonic saline.

e $\mathrm{P}<0.05$.

f $\mathrm{P}<0.001$ Group Sand Group T vs Group M.

g $\mathrm{P}<0.01$ Group T and Group M vs Group S.

\section{Discussion}

We evaluated the efficacy of IA administration of levobupivacaine-tenoxicam combination with either tramadol or morphine on reducing postoperative pain knee arthroscopies. We found that addition of morphine to levobupivacaine-tenoxicam combination decreased postoperative pain and analgesic consumption compared to tramadol. Effective pain management shortens hospital stay, improves recovery from knee surgery, and contributes to early rehabilitation. Many IA drugs such as local anesthetics, opioids, NSAIDs, clonidine, and neostigmine have been used for postoperative pain relief after arthroscopic knee surgery (6-11); however, none of them have yet been identified to be the ideal method. Although local anesthetics, mostly bupivacaine, have been found to be effective for postoperative pain, they are short lived and patients usually require supplementary analgesia (11). On the other hand, IA bupivacaine can produce toxic effects on chondrocytes $(2,3)$. Levobupivacaine is S-enantiomer of bupivacaine and has a longer effect compared to bupivacaine. There is no study regarding levobupivacaine toxicity in IA administration and data on its IA use is limited (12-16). In a study by Kazak Bengisun et al. (16), IA levobupivacaine and bupivacaine were compared with saline (control); both local anesthetics decreased pain scores at rest and after movement and consumption of postoperative tramadol compared saline. Moreover, bupivacaine and levobupivacaine produced similar effects on pain and analgesic consumption when administered intra-articularly.

We preferred to use levobupivacaine in our study after the studies showing bupivacaine's toxic effects on chondrocytes; moreover, there are only a few studies in the literature using IA levobupivacaine. The IA administration of NSAIDs was effective in improving analgesia after arthroscopic knee surgery. Using both a local anesthetic and a long-acting NSAID provides the advantage of additive synergic effect. In addition, the injection of a NSAID into the joint cavity may play a role in pain control, particularly when a significant inflammatory component to the IA pathology is found $(17,18)$. Different NSAIDs such as piroxicam (18), lornoxicam (19), and tenoxicam $(9,20)$ have been used intra-articularly. Tenoxicam was found to be suitable agent for IA injection since it does not suppress chondroformative processes and it is a long acting nonsteroidal agent. It has been used intra-articularly, alone or in combination with local anesthetics $(6,9,20$, 21). In all of these studies, the tenoxicam IA dose was 20 $\mathrm{mg}$. Moreover, we used $20 \mathrm{mg}$ of tenoxicam intra-articularly for postoperative pain management in different types of arthroscopies in a non-published, but a presented (in European Regional Anaesthesia Congress in 2005), study.

Talu et al. (21) demonstrated that IA administration of bupivacaine plus tenoxicam provides good analgesia at rest and during active-passive motion in the postoperative period. In the presence of these literatures and our previous experience, we preferred to combine $20 \mathrm{mg}$ of tenoxicam with levobupivacaine in both study groups. Opiates such as morphine and tramadol have peripheral and central analgesic effects, and there is evidence opiate receptors presence at the terminals of afferent peripheral nerves; therefore, administration of opiates peripherally might provide a significant analgesic effect $(22,23)$. Stein et al. showed that low doses of IA morphine, injected on the completion of arthroscopic knee surgery, can produce postoperative analgesia via activation of local opioid receptors in the knee joint (24). This peripheral effect of narcotic-like analgesics could explain why the IA administration of morphine and tramadol could provide a satisfactory pain relief state as well as fewer systemic adverse effects (25). Morphine, as an opioid, and bupivacaine, as a local anesthetic, alone or compound form, are frequently injected into the IA space of the knee joint after arthroscopic surgery $(26,27)$. Gurkan et al. (28) used $2 \mathrm{mg}$ of morphine and $0.25 \%$ bupivacaine combination and Joshi et al. (29) used $5 \mathrm{mg}$ of morphine and $0.25 \%$ bupivacaine combination versus saline alone. In both studies, VAS scores were significantly lower in IA morphine and bupivacaine combination than was in IA saline. Similar to the combination of these two studies, we used levobupivacaine and morphine combination and found significantly lower VAS scores in comparison to saline alone. Senthilkumaran et al. (30) demonstrated that IA combination of $10 \mathrm{mg}$ of morphine and $20 \mathrm{~mL}$ of 
Oral EG et al.

$0.5 \%$ bupivacaine reduces requirement for systemic opiate analgesia after arthroscopic ACL reconstruction than morphine alone does.

Boden et al. (26) and McSwiney et al. (31) used IA morphine-bupivacaine combination versus saline as control group and reported significantly lower supplementary analgesia and lower analgesic requirements, respectively. In our study, total analgesic consumption was significantly lower in our local anesthetic with tenoxicam and morphine group compared to saline group, which was in accordance with the mentioned studies.

Tramadol is a weak opioid agonist (selective $\mu$ receptor). Garlicki J et al. (32) showed that it inhibits nociception, edema, and functional impairment of the paw after its local direct administration to the inflamed knee joint, the same as morphine does. There are a few studies investigating analgesic effects of its IA administration after arthroscopic knee surgery $(33,34)$. There are only two studies using tramadol and local anesthetic combination intra-articularly. In both studies, bupivacaine was used as local anesthetic $(9,35)$. In Tuncer et al. study (35), IA combination of $0.25 \%$ bupivacaine and $100 \mathrm{mg}$ of tramadol produced significantly lower postoperative VAS scores than $0.25 \%$ bupivacaine alone did. In a recent study, Zeidan et al. (5) found that a combination of tramadol (100 mg) with $0.25 \%$ bupivacaine after arthroscopic knee surgery provides a lower VAS pain scores, a longer duration of analgesia, and a decrease in the 24-hour consumption of rescue analgesia without any side effects when compared with groups receiving bupivacaine or tramadol alone. We had lower VAS scores, decreased 24hour total analgesic consumption in local anesthetic administration of tenoxicam-tramadol in comparison with saline group, which was similar to abovementioned studies. Jazayeri et al. compared the efficacy of morphine and tramadol on postoperative pain after arthroscopic knee surgery (25). They had comparable VAS scores between two groups. Hosseini et al. study was the first one that compared IA administration of morphinebupivacaine and tramadol-bupivacaine combinations in patients undergoing knee surgery (4). In their study, VAS scores were significantly less in morphine-bupivacaine and tramadol-bupivacaine groups in comparison with the control group. Moreover, analgesic duration was longer and analgesic consumption was substantially less in the morphine-bupivacaine group than were in tramadol-bupivacaine and control groups. Similar to the study by Hosseini et al. both of our study groups had lower VAS scores than control group had. In addition, duration of analgesia and postoperative 24-hour analgesic consumption was lower in levobupivacaine-tenoxicam-morphine and saline groups in comparison with levobupivacainetenoxicam-tramadol group. The adverse effects were comparable between the three groups.

Combining tramadol or morphine with other drugs can decrease the high postoperative dosages of administered opiates and thus, can lead to less drug adverse effects $(4,36)$. Several studies have suggested ways to manage postoperative pain after arthroscopy, some of which are IA injection of different drugs combination. However, no study had compared using IA combination of levobupivacaine-tenoxicam-morphine with using levobupivacaine-tenoxicam-tramadol in patients undergoing arthroscopic knee surgery.

We concluded that IA levobupivacaine-tenoxicam-morphine provides effective pain relief, longer analgesic duration, and less analgesic requirement when compared with IA levobupivacaine-tenoxicam-tramadol and saline after knee arthroscopic surgery.

\section{Authors' Contributions}

Ebru Gelici Oral, Hale Dobrucali: Study concept and design, acquisition of data, drafting the manuscript, and critical revision of the manuscript for important intellectual content. Ayse Hanci: Critical revision of the manuscript for important intellectual content, statistical analysis, and study supervision. Gulcihan Ulufer Sivrikaya: Acquisition of data, analysis and interpretation of data, drafting the manuscript, critical revision of the manuscript for important intellectual content, statistical analysis, and administrative, technical, and material support. Leyla Turkoglu Kilinc: Acquisition of data, drafting of the manuscript, administrative, technical, and material support, and study supervision.

\section{References}

1. Ekman EF, Wahba M, Ancona F. Analgesic efficacy of perioperative celecoxib in ambulatory arthroscopic knee surgery: a doubleblind, placebo-controlled study. Arthroscopy. 2006;22(6):635-42.

2. Gomoll AH, Yanke AB, Kang RW, Chubinskaya S, Williams JM, Bach BR, et al. Long-term effects of bupivacaine on cartilage in a rabbit shoulder model. Am J Sports Med. 2009;37(1):72-7.

3. Chu CR, Coyle CH, Chu CT, Szczodry M, Seshadri V, Karpie $\mathrm{JC}$, et al. In vivo effects of single intra-articular injection of 0.5\% bupivacaine on articular cartilage. J Bone Joint Surg Am. 2010;92(3):599-608.

4. Hosseini $\mathrm{H}$, Abrisham SM, Jomeh $\mathrm{H}$, Kermani-Alghoraishi M, Ghahramani R, Mozayan MR. The comparison of intraarticular morphine-bupivacaine and tramadol-bupivacaine in postoperative analgesia after arthroscopic anterior cruciate ligament reconstruction. Knee Surg Sports Traumatol Arthrosc. 2012;20(9):1839-44.

5. Zeidan A, Kassem R, Nahleh N, Maaliki H, El-Khatib M, Struys MM, et al. Intraarticular tramadol-bupivacaine combination prolongs the duration of postoperative analgesia after outpatient arthroscopic knee surgery. Anesth Analg. 2008;107(1):292-9.

6. Alagol A, Calpur OU, Usar PS, Turan N, Pamukcu Z. Intraarticular analgesia after arthroscopic knee surgery: comparison of neostigmine, clonidine, tenoxicam, morphine and bupivacaine. Knee Surg Sports Traumatol Arthrosc. 2005;13(8):658-63.

7. Reuben SS, Sklar J, El-Mansouri M. The preemptive analgesic effect of intraarticular bupivacaine and morphine after ambulatory arthroscopic knee surgery. Anesth Analg. 2001;92(4):923-6.

8. Joshi W, Reuben SS, Kilaru PR, Sklar J, Maciolek H. Postoperative analgesia for outpatient arthroscopic knee surgery with intraarticular clonidine and/or morphine. Anesth Analg. 2000;90(5):1102-6.

9. Cook TM, Tuckey JP, Nolan JP. Analgesia after day-case knee arthroscopy: double-blind study of intra-articular tenoxicam, intra-articular bupivacaine and placebo. $\mathrm{Br} J$ Anaesth. 1997;78(2):163-8. 
10. Batra YK, Mahajan R, Bangalia SK, Nagi ON, Dhillon MS. Bupivacaine/ketamine is superior to intra-articular ketamine analgesia following arthroscopic knee surgery. Can J Anaesth. 2005;52(8):832-6.

11. Raja SN, Dickstein RE, Johnson CA. Comparison of postoperative analgesic effects of intraarticular bupivacaine and morphine following arthroscopic knee surgery. Anesthesiology. 1992;77(6):1143-7.

12. Bhattacharjee DP, Biswas C, Haldar P, Ghosh S, Piplai G, Rudra JS Efficacy of intraarticular dexamethasone for postoperative analgesia after arthroscopic knee surgery. J Anaesthesiol Clin Pharmacol.2014;30(3):387-90.

13. Sahin SH, Memis D, Celik E, Sut N. Postarthroscopy analgesia us ing intraarticular levobupivacaine and intravenous dexketoprofen trometamol. Knee Surg Sports Traumatol Arthrosc. 2014.

14. Isik C, Demirhan A, Yetis T, Oktem K, Sarman H, Tekelioglu UY, et al. Efficacy of intraarticular application of ketamine or ketamine-levobupivacaine combination on post-operative pain after arthroscopic meniscectomy. Knee Surg Sports Traumatol Arthrosc. 2014.

15. Koltka K, Koknel-Talu G, Asik M, Ozyalcin S. Comparison of efficacy of intraarticular application of magnesium, levobupivacaine and lornoxicam with placebo in arthroscopic surgery. Knee Surg Sports Traumatol Arthrosc. 2011;19(11):1884-9.

16. Kazak Bengisun Z, Aysu Salviz E, Darcin K, Suer H, Ates Y. Intraarticular levobupivacaine or bupivacaine administration decreases pain scores and provides a better recovery after total knee arthroplasty. J Anesth. 2010;24(5):694-9.

17. Mert T, Gunes Y, Guven M, Gunay I, Gocmen C. Differential effects of lidocaine and tramadol on modified nerve impulse by 4-aminopyridine in rats. Pharmacology. 2003;69(2):68-73.

18. Izdes S, Orhun S, Turanli S, Erkilic E, Kanbak O. The effects of preoperative inflammation on the analgesic efficacy of intraarticular piroxicam for outpatient knee arthroscopy. Anesth Analg. 2003;97(4):1016-9.

19. Ersan O, Akkaya T, Arik E, Ates Y. Intra-articular levobupivacaine, lornoxicam and morphine analgesia after knee arthroscopy: a randomized, controlled trial. Acta Orthop Traumatol Turc. 2012;46(6):411-5.

20. Guler G, Karaoglu S, Velibasoglu H, Ramazanogullari N, Boyaci A. Comparison of analgesic effects of intra-articular tenoxicam and morphine in anterior cruciate ligament reconstruction. Knee Surg Sports Traumatol Arthrosc. 2002;10(4):229-32.

21. Talu GK, Ozyalcin S, Koltka K, Erturk E, Akinci O, Asik M, et al. Comparison of efficacy of intraarticular application of tenoxicam, bupivacaine and tenoxicam: bupivacaine combination in arthroscopic knee surgery. Knee Surg Sports Traumatol Arthrosc. 2002;10(6):355-60.

22. Graham NM, Shanahan MD, Barry P, Burgert S, Talkhani I. Postoperative analgesia after arthroscopic knee surgery: a randomized, prospective, double-blind study of intravenous regional analge- sia versus intra-articular analgesia. Arthroscopy. 2000;16(1):64-6.

23. Stein C, Gramsch C, Herz A. Intrinsic mechanisms of antinociception in inflammation: local opioid receptors and beta-endorphin. J Neurosci. 1990;10(4):1292-8.

24. Stein C, Comisel K, Haimerl E, Yassouridis A, Lehrberger K, HerZ $A$, et al. Analgesic effect of intraarticular morphine after arthroscopic knee surgery. N Engl J Med.1991;325(16):1123-6.

25. Jazayeri SM, Mosaffa F, Abbasian M, Hosseinzadeh HR. Comparing the efficacy of intra-articular application of morphine and tramadol on postoperative pain after arthroscopic knee surgery. Anesth Pain Med. 2012;2(1):28-31.

26. Boden BP, Fassler S, Cooper S, Marchetto PA, Moyer RA. Analgesic effect of intraarticular morphine, bupivacaine, and morphine/bupivacaine after arthroscopic knee surgery. Arthroscopy. 1994;10(1):104-7.

27. Marchal JM, Delgado-Martinez AD, Poncela M, Valenzuela J, de Dios Luna J. Does the type of arthroscopic surgery modify the analgesic effect of intraarticular morphine and bupivacaine? A preliminary study. Clin J Pain. 2003;19(4):240-6.

28. Gurkan Y, Kilickan L, Buluc L, Muezzinoglu S, Toker K. Effects of diclofenac and intra-articular morphine/bupivacaine on postarthroscopic pain control. Minerva Anestesiol. 1999;65(10):741-5.

29. Joshi GP, McCarroll SM, O'Brien TM, Lenane P. Intraarticular analgesia following knee arthroscopy. Anesth Analg. 1993;76(2):333-6.

30. Senthilkumaran S, Tate R, Read JR, Sutherland AG. Intra-articular morphine and bupivicaine for post-operative analgesia in anterior cruciate ligament reconstruction: a prospective randomised controlled trial. Knee Surg Sports Traumatol Arthrosc. 2010;18(6):731-5.

31. McSwiney MM, Joshi GP, Kenny P, McCarroll SM. Analgesia following arthroscopic knee surgery. A controlled study of intra-articular morphine, bupivacaine or both combined. Anaesth Intensive Care.1993;21(2):201-3.

32. Garlicki J, Dorazil-Dudzik M, Wordliczek J, Przewlocka B. Effect of intraarticular tramadol administration in the rat model of knee joint inflammation. Pharmacol Rep. 2006;58(5):672-9.

33. Akinci SB, Saricaoglu F, Atay A, Doral MN, Kanbak M. Analgesic effect of intra-articular tramadol compared to morphine after arthroscopic knee surgery. Can J Anaesth. 2003;50(4):423-4.

34. Alagol A, Calpur OU, Kaya G, Pamukcu Z, Turan FN. The use of intraarticular tramadol for postoperative analgesia after arthroscopic knee surgery: a comparison of different intraarticular and intravenous doses. Knee Surg Sports Traumatol Arthrosc. 2004;12(3):184-8.

35. Tuncer B, Babacan A, Arslan M. Preemptive intraarticular tramadol for pain control after arthroscopic knee surgery. Agri. 2007;19(1):42-9.

36. Zeraati F, Araghchian M, Farjoo MH. Ascorbic Acid interaction with analgesic effect of morphine and tramadol in mice. Anesth Pain Med. 2014;4(3):e19529. 